\title{
The Wake-Promoting Hypocretin/Orexin Neurons Change Their Response to Noradrenaline after Sleep Deprivation
}

\author{
Jeremy Grivel, ${ }^{1}$ Vesna Cvetkovic, ${ }^{1}$ Laurence Bayer, ${ }^{1}$ Danièle Machard, ${ }^{1}$ Irene Tobler, ${ }^{2}$ Michel Mühlethaler, ${ }^{1}$ and \\ Mauro Serafin ${ }^{1}$ \\ ${ }^{1}$ Département des Neurosciences fondamentales, Centre Médical Universitaire, 1211 Geneva 4, Switzerland, and 2Institute of Pharmacology and Toxicology, \\ University of Zurich, 8057 Zurich, Switzerland
}

\begin{abstract}
Sleep deprivation is accompanied by the progressive development of an irresistible need to sleep, a phenomenon whose mechanism has remained elusive. Here, we identified for the first time a reflection of that phenomenon in vitro by showing that, after a short $2 \mathrm{~h}$ period of total sleep deprivation, the action of noradrenaline on the wake-promoting hypocretin/orexin neurons changes from an excitation to an inhibition. We propose that such a conspicuous modification of responsiveness should contribute to the growing sleepiness that accompanies sleep deprivation.
\end{abstract}

Key words: arousal; hypothalamus; sleep; waking; noradrenaline; orexin

\section{Introduction}

Sleep-deprivation studies in humans and many other mammals have repeatedly shown a homeostatic regulation of sleep, consisting of an increase in electroencephalogram (EEG) slow-wave activity during recovery sleep (for review, see Borbely and Achermann, 2000; Tobler, 2000). Slow-wave activity is considered an intensity parameter of sleep that reflects the homeostatic process. The increasing sleep pressure and subjective sleepiness during the deprivation is accompanied by an increase in $\theta$ activity in the waking EEG (Finelli et al., 2000) and correlates with the subsequent increase in slow-wave activity during sleep. However, in vitro cellular correlates of the sleep-deprived (SD) state, which would be relevant to sleepiness, have not yet been uncovered.

The neurons of the lateral hypothalamic and perifornical areas (LHA/PF) that express hypocretin/orexin (hcrt/orx) (de Lecea et al., 1998; Sakurai et al., 1998) are thought to play a major role in promoting wakefulness (for review, see Siegel et al., 2001; Beuckmann and Yanagisawa, 2002; Sutcliffe and de Lecea, 2002; Taheri et al., 2002). Alteration of the hcrt/orx system is associated with narcolepsy in dogs, mice, and humans (Chemelli et al., 1999; Lin et al., 1999; Nishino et al., 2000; Peyron et al., 2000; Thannickal et al., 2000; Hara et al., 2001), and one dominating feature of that pathology is an abnormal sleepiness.

We thus hypothesized that sleepiness associated with sleep deprivation might be reflected on hcrt/orx neurons. Because preliminary studies have indicated that rat hcrt/orx neurons are consistently excited by noradrenaline (Bayer et al., 2005), a major transmitter of arousal, we examined in vitro whether this re-

Received Jan. 12, 2005; revised March 14, 2005; accepted March 15, 2005

This work was supported by grants from the Swiss Fonds National (M.M., M.S., and I.T.).

Correspondence should be addressed to Michel Mühlethaler, Département des Neurosciences fondamentales, Centre Médical Universitaire, 1 Rue Michel-Servet, 1211 Geneva 4, Switzerland. E-mail: michel.muhlethaler@ medecine.unige.ch.

DOI:10.1523/JNEUROSCI.0666-05.2005

Copyright $\odot 2005$ Society for Neuroscience $\quad$ 0270-6474/05/254127-04\$15.00/0 sponse was modified after a short-lasting period of sleep deprivation.

Parts of this work have been published previously in abstract form (Grivel et al., 2004).

\section{Materials and Methods}

Slice preparation and electrophysiological recordings. Young Sprague Dawley rats (from the animal facility of the Geneva Medical Center or Charles River Laboratories, Saint-Aubin les Elbeuf, France) were maintained in a $12 \mathrm{~h}$ light/dark cycle (lights on from 8:00 A.M. to 8:00 P.M.) and treated according to the regulations of the Swiss Federal Veterinary Office. At the end of either the sleep deprivation or the control period (see Results), hypothalamic coronal brain slices (thickness, 250-300 $\mu \mathrm{m}$ ) containing the hcrt/orx neurons were obtained. They were left to recover for $1 \mathrm{~h}$ (until 11:00 A.M.) at room temperature in artificial CSF (ACSF) containing the following (in mM): $130 \mathrm{NaCl}, 5 \mathrm{KCl}, 1.25 \mathrm{KH}_{2} \mathrm{PO}_{4}, 1.3 \mathrm{MgSO}_{4}, 20$ $\mathrm{NaHCO}_{3}, 10$ glucose, and $2.4 \mathrm{CaCl}_{2}$ (bubbled with $95 \% \mathrm{O}_{2}$ and $5 \% \mathrm{CO}_{2}$ ). Individual slices were then transferred to a thermoregulated $\left(32^{\circ} \mathrm{C}\right)$ recording chamber, in which they were immersed and continuously superfused at $4-5 \mathrm{ml} / \mathrm{min}$ with ACSF. The chamber was mounted on an upright microscope (Axioskop; Zeiss, Oberkochen, Germany) equipped with an infrared camera.

Electrophysiological experiments were then started and, in both conditions, were performed for only 2 h (11:00 A.M. to 1:00 P.M.; see Results). Whole-cell recordings were obtained with patch pipettes that were pulled on a DMZ universal puller (Zeitz-Instrumente, Munich, Germany) from borosilicate glass capillaries (GC150F-10; Clark Electromedical Instruments, Edenbridge, UK). The pipettes were filled with a solution [8 $\mu \mathrm{l}$ when performing single-cell reverse transcription (RT)PCR] containing the following (in $\mathrm{mM}$ ): $126 \mathrm{KMeSO}_{4}, 4 \mathrm{KCl}, 5 \mathrm{MgCl}_{2}$, 0.1 BAPTA, 10 HEPES, 8 phosphocreatine, 3 ATP, and 0.1 GTP, pH 7.3 (285-300 mOsm). Whole-cell recordings were performed in the currentclamp mode using an Axopatch 200B amplifier (Axon Instruments, Union City, CA). The membrane potential values were not compensated for junction potential (estimated at $-9.6 \mathrm{mV}$ ). Noradrenaline (Sigma, Schnelldorf, Germany) and tetrodotoxin (Latoxan, Rosans, France) were applied at known concentrations in the bath. Synaptic blockade was 
achieved by lowering calcium and increasing magnesium $\left(0.1 \mathrm{mM} \mathrm{Ca}^{2+}\right.$; $10 \mathrm{~mm} \mathrm{Mg}^{2+}$ ).

Single-cell RT-PCR. At the end of the recording, the content of the cell was aspirated under visual control into the recording pipette (3-5 M $\Omega$ ) and expelled into a test tube in which reverse transcription was performed. hcrt/orx cDNAs were synthesized overnight at $37^{\circ} \mathrm{C}$ in a total reaction volume of $10 \mu \mathrm{l}$ containing random hexamer primers $(25 \mu \mathrm{M}$; Roche Diagnostics, Mannheim, Germany), the four deoxyribonucleotide triphosphates (2.5 mM; Invitrogen, Basel, Switzerland), dithiothreitol (10 mm; Sigma, Buchs, Switzerland), RNase inhibitor (20 U; Promega, Wallisellen, Switzerland), and reverse transcriptase (Superscript II; 200 $\mathrm{U}$; Invitrogen). hcrt/orx cDNAs were then amplified by PCR using the following primers: sense, $5^{\prime}$-TGC CGT CTC TAC GAA CTG TTG CAC G-3'; antisense, 5' -AGG GAT ATG GCT CTA GCT CTG CGC C-3' . RT reaction $(10 \mu \mathrm{l})$, Taq polymerase (Herculase Hotstart DNA polymerase; $2.5 \mathrm{U}$; Stratagene, Amsterdam, The Netherlands), deoxyribonucleotide triphosphates ( $0.25 \mathrm{~mm}$; Invitrogen), and a $0.1 \mu \mathrm{m}$ concentration of each primer were added to a buffer solution (final volume, $50 \mu \mathrm{l}$ ). After $5 \mathrm{~min}$ at $94^{\circ} \mathrm{C}, 22$ cycles $\left(94^{\circ} \mathrm{C}\right.$ for $30 \mathrm{~s} ; 72^{\circ} \mathrm{C}$ for $2 \mathrm{~min}$ ) of PCR were run, followed by a final elongation period of $10 \mathrm{~min}$ at $72^{\circ} \mathrm{C}$. A second round of PCR was performed with $3 \mu \mathrm{l}$ of the first PCR product under similar conditions for 35 cycles. PCR products were separated and visualized in ethidium bromide-stained agarose gel $(1 \%)$ by electrophoresis. The predicted size of the PCR fragment was $189 \mathrm{bp}$. In a few experiments, the pipette content was expelled first into tubes containing $20 \mathrm{U}$ of RNase inhibitor (Stratagene) for blocking RNase activity and $20 \mathrm{U}$ of DNase I (Stratagene) for digestion of genomic DNA. Samples were then incubated at $37^{\circ} \mathrm{C}$ for $30 \mathrm{~min}$, followed by incubation at $75^{\circ} \mathrm{C}$ for $5 \mathrm{~min}$ to inactivate the DNase. The rest of the RT-PCR procedure was as described above.

Statistics. To evaluate the degree of independence between the two experimental conditions [control condition (CC) and SD] and the two types of effects observed (regrouped into pure excitatory vs inhibitory component), we tested whether the variation in the distributions arises from a systematic factor or from a random fluctuation using the $\chi^{2}$ independence test (S-PLUS 6 software; Insightful Corporation, Reinach, Switzerland).

\section{Results}

Identification of hcrt/orx cells was done according to criteria devised previously and detailed here. In two consecutive published studies using neurobiotin injection and hcrt/orx immunohistochemistry (Eggermann et al., 2003; Bayer et al., 2005), implying a total of 21 cells, we were indeed able to demonstrate that every single cell in the LHA/PF that had a low-threshold spike (LTS) followed by a depolarizing afterpotential (DAP) and an $I_{\mathrm{h}}$-dependent rectification was an hcrt/orx cell. An additional five cells, of which one is shown here to demonstrate these basic electrophysiological criteria [Fig. $1 B$, arrow (LTS) and asterisk (DAP), $C$, ( $I_{\mathrm{h}}$-dependent rectification)], were also all hcrt/orx positive [using the same protocols as those used by Bayer et al. (2005)]. Our basic identification criteria are also supported by single-cell RT-PCR studies. Indeed, of 21 cells that had the electrophysiological properties of hcrt/orx neurons, 19 expressed hcrt/orx (data not shown). In contrast, none of the cells $(n=10)$ that were deemed electrophysiologically to be melanin-concentrating hormone neurons (Eggermann et al., 2003) expressed hcrt/orx. It is noteworthy that, in addition, although care was taken to avoid harvesting the nucleus for the reported RT-PCR studies, an additional six electrophysiologically characterized hcrt/orx cells were analyzed in the presence of DNase to avoid genomic DNA contamination (see Materials and Methods). All six of them expressed hcrt/orx (one is shown in Fig. $1 F$ ). The following study was thus done exclusively with cells that had the electrophysiological criteria reported above. In detail, of a total of 125 recorded neurons in the LHA/PF, 48 were hcrt/orx according to these criteria. Of those 48 cells, 34 were found to be stable

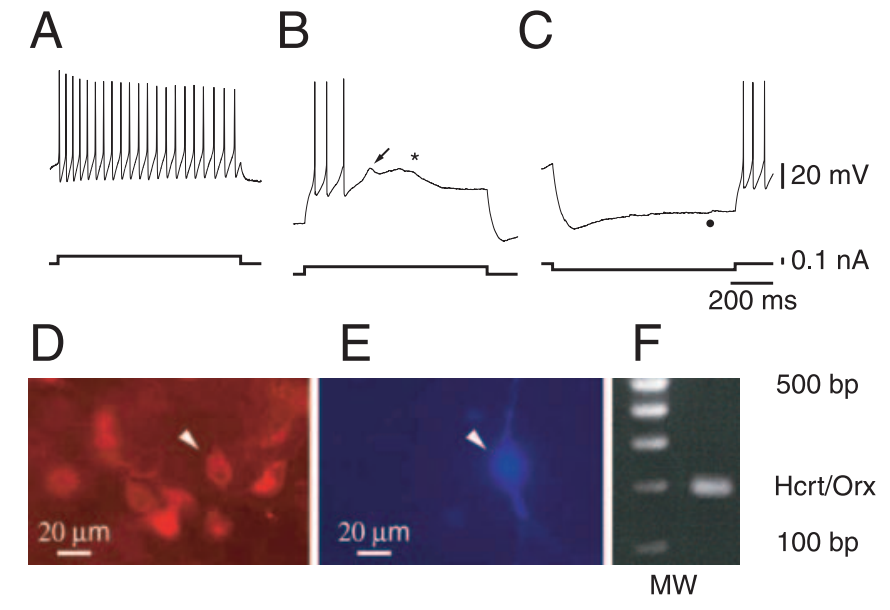

Figure 1. Identification of hert/orx cells. $A$, Properties of hcrt/orx cells, with tonic firing when depolarized by a current pulse at rest. $\boldsymbol{B}$, Presence of an LTS (arrow) and a depolarizing afterpotential $\left(^{*}\right)$ when depolarized from a hyperpolarized level. $\boldsymbol{C}, I_{\mathrm{h}}$-dependent membrane rectification (). D, Field of immunohistochemically identified hort/orx cells; the one (arrowhead) for which the recording is presented above is shown in $\boldsymbol{E}$ to be neurobiotin positive (arrowhead). $\boldsymbol{F}$, Gel demonstrating the identification of another hort/orx neuron using singlecell RT-PCR (see Materials and Methods). MW, Molecular weight.

enough ( $0.5 \mathrm{~h}$ of recording) for a full pharmacological appraisal and thus were used in the present study.

To study hcrt/orx neurons in a CC and an SD condition, avoiding circadian influences, the following experimental protocol was used (Fig. 2). After a normal cycle of sleep and waking, CC rats $(n=13$ animals) were allowed to sleep for $2 \mathrm{~h}(8: 00-10: 00$ A.M.), starting at the onset of the physiological "rest" period (8:00 A.M.). In that condition, when their behavior was continuously monitored by video, rats slept $>70 \%$ of the time $(80.3 \pm$ $1.63 \% ; n=36)$. In contrast, rats in the SD group $(n=10)$ were kept fully awake, being gently sleep deprived (V. V. Vyazovskiy et al., 2004) for the same $2 \mathrm{~h}$ interval. The well known homeostatic changes in the sleep EEG after sleep deprivation have been shown to change in proportion to the duration of previous wakefulness and are consistent with the changes after spontaneous episodes of waking (Tobler and Borbely, 1986; Huber et al., 2000). In both control and SD conditions, hypothalamic coronal brain slices containing the hcrt/orx cells were obtained at the same hour (10:00 A.M.) and left to recover for $1 \mathrm{~h}$ (until 11:00 A.M.). Electrophysiological experiments were then started and, in both conditions, were performed for only 2 h (11:00 A.M. to 1:00 P.M.). Based on our studies in which the EEG was measured, we hypothesized that the consequences of the sleep deprivation would be manifested during that period (Alfoldi et al., 1990; Tobler et al., 1996; V. Vyazovskiy et al., 2004).

When comparing first the mean resting potentials of hcrt/orx neurons in the CC $(n=16)$ and SD condition $(n=18)$, we found no difference between the two conditions (mean \pm SEM, $-46.99 \pm 1.07 \mathrm{mV}$ for CC vs $-45.36 \pm 0.91 \mathrm{mV}$ for SD; Student's $t$ test; $p>0.05)$. Similarly, we found no difference in the resting firing rates of hcrt/orx neurons between CC and the SD condition $(1.23 \pm 0.25 \mathrm{~Hz}$ for CC vs $1.17 \pm 0.25 \mathrm{~Hz}$ for SD; $p>0.05)$.

We then tested the effect of noradrenaline, briefly bath applied at $100 \mu \mathrm{M}$, in both conditions. In the CC, we found that most hcrt/orx cells ( 12 of $16 ; 75.0 \%$ ) were exclusively excited by noradrenaline (Fig. $3 A_{1}$ ), whereas a minority ( 4 of $16 ; 25.0 \%$; data not shown) displayed an inhibitory component to the response [pure inhibitory ( 2 of 16 ) or biphasic inhibitory/excitatory ( 2 of 


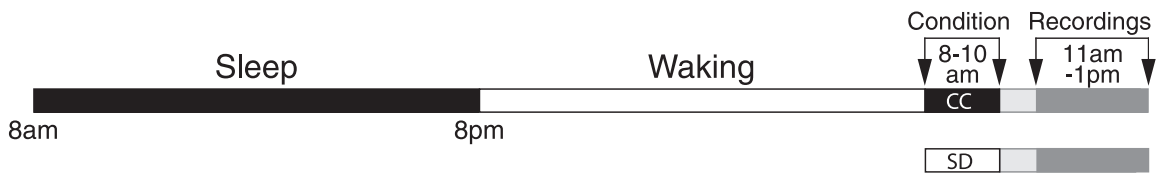

Figure 2. Protocol for the $\mathrm{CC}$ and the SD condition.

\section{Control (CC)}

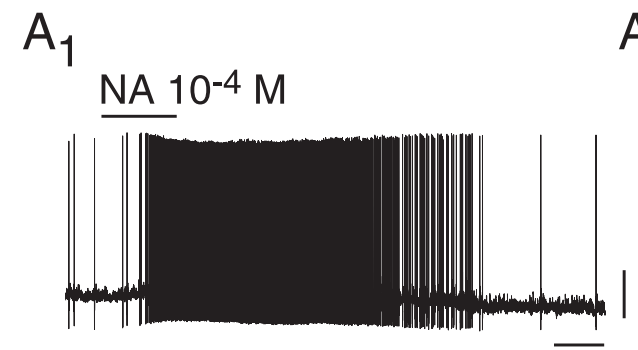

$\mathrm{A}_{2}$

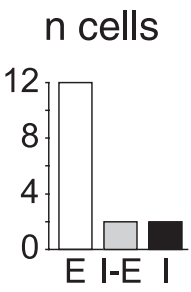

Sleep deprived (SD)

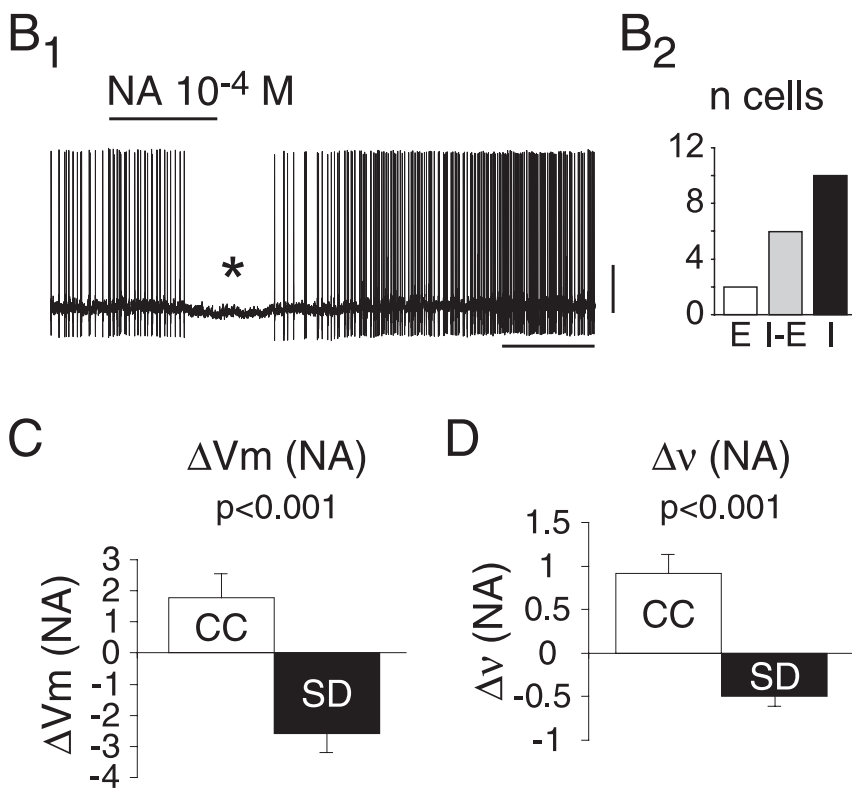

Figure 3. Effect of noradrenaline (NA) in the CC and the SD condition. $\boldsymbol{A}_{\boldsymbol{1}}$, Effect of noradrenaline in the CC. $\boldsymbol{A}_{2}$, Summary of noradrenaline effects in the CC. $\boldsymbol{B}_{\boldsymbol{1}}$, Effect of noradrenaline (asterisk) after sleep deprivation. $\boldsymbol{B}_{2}$, Summary of noradrenaline (asterisk) effects after sleep deprivation. $\boldsymbol{C}, \boldsymbol{D}$, Comparison of noradrenaline effects on membrane potential and firing rate in the CC $(\boldsymbol{C})$ and the SD condition (D). Calibration: $\boldsymbol{A}_{\boldsymbol{1}}, \boldsymbol{B}_{\boldsymbol{1}}, 20 \mathrm{mV}, 60$ s. E, Excitation; I, inhibition; $\mathrm{I}-\mathrm{E}$, inhibition/excitation.

16)]. The results for the $C C$ are summarized in Figure $3 A_{2}$. In a striking contrast, after sleep deprivation, almost all cells ( 16 of 18 ; $88.9 \%)$ displayed an inhibitory component in the response to noradrenaline [pure inhibitory (10 of 18) (Fig. $3 B_{1}$ ) or biphasic inhibitory/excitatory ( 6 of 18$)]$. Only a small minority of cells (2 of $18 ; 11.1 \%$; data not shown) were exclusively excited by noradrenaline in the SD condition. The results for the SD condition are summarized in Figure $3 B_{2}$. This change in the response of a population of cells to noradrenaline was found to be highly significant ( $p<0.001 ; \chi^{2}$ test; see Materials and Methods).

To further quantify the results, the variation in membrane potential and firing frequency in response to noradrenaline in both conditions was compared. It was found that the variation in membrane potential in response to noradrenaline differed in a highly significant manner (Student's $t$ test; $p<0.001$ ) (Fig. 3C) between the CC $\left(\Delta V_{\mathrm{m}}=+1.78 \pm 0.79 \mathrm{mV} ; n=16\right)$ and the SD condition $\left(\Delta V_{\mathrm{m}}=-2.59 \pm\right.$ $0.63 \mathrm{mV} ; n=18)$. Similarly, the variation in firing frequency in response to noradrenaline also differed in a highly significant manner $(p<0.001)$ (Fig. 3D) between the CC $(\Delta \nu=+0.92 \pm 0.22 \mathrm{~Hz} ; n=16)$ and the SD condition $(\Delta \nu=$ $-0.5 \pm 0.11 \mathrm{~Hz} ; n=17)$.

We finally tested whether the site of noradrenaline action on hcrt/orx cells is presynaptic or postsynaptic in either condition. We first found that the depolarizing effect characteristic of the CC was present in a high-magnesium/low-calcium solution $(n=$ 3 ), thus indicating that it is postsynaptic. We then found similar results for the SD condition, because both the pure inhibitory $(n=3)$ type of response and the mixed inhibitory/excitatory response persisted in either tetrodotoxin $(n=3)$ or a highmagnesium/low-calcium solution $(n=3)$.

\section{Discussion}

The present study shows that $2 \mathrm{~h}$ of total sleep deprivation is sufficient to change the responses of hcrt/orx neurons to noradrenaline from being mostly excitatory ( $75 \%$ of cells) in control conditions to mostly inhibitory (nearly $90 \%$ of cells) after sleep deprivation. Both response types are postsynaptic.

Although the mechanism underlying this change was not investigated in the present report, it is noteworthy that it does not involve a modification of the resting membrane potential or the spontaneous firing rate of the hcrt/orx cells. Also of importance is the observation that inhibitory and excitatory responses to noradrenaline are still present when synaptic transmission is blocked. This latter result shows that the change induced by sleep deprivation is expressed postsynaptically. It could depend on the noradrenergic receptors themselves or the pathways linking them to channels modulated by their activation. Additional studies will be required to address these issues. Interestingly, in that respect, immunohistochemical studies of hcrt/orx neurons have identified recently that, in rats, both $\alpha_{1}$ - and $\alpha_{2}$-noradrenergic receptors can be present on these cells (B. E. Jones, personal communication).

As discussed in our recent report of the excitatory effects of noradrenaline on hcrt/orx neurons in rats (Bayer et al., 2005), we do not have a firm explanation for the hyperpolarizing effect reported for noradrenaline on mice hcrt/orx neurons in the absence of sleep deprivation (Li et al., 2002; Yamanaka et al., 2003; $\mathrm{Li}$ and van den Pol, 2005). One is left with the speculation that it could be attributable to a species difference. Additional studies in mice in different circadian and homeostatic conditions might eventually shed light on this intriguing discrepancy.

Most recent sleep-deprivation studies have dealt with the molecular aspects of sleep homeostasis. Gene expression studies during the sleep-waking cycle and after sleep deprivation have thus indicated that different processes might be favored in one or the other state (Cirelli et al., 2004). During wakefulness, genes related to excitatory synaptic transmission and synaptic potentiation are expressed preferentially, whereas during sleep, genes implicated in synaptic inhibition and depression as well as protein synthesis are favored. These evidences support the notion that one important role of sleep might be related to synaptic plasticity (Tononi and Cirelli, 2003; Huber et al., 2004). However, these studies, 
which deal mainly with the homeostatic function of sleep, do not provide an insight into a cellular mechanism of sleepiness, which might or might not be directly related to the homeostatic process.

To our knowledge, the findings reported here represent the first neurobiological trace of sleep deprivation discernible in vitro that is directly relevant to the phenomenon of sleepiness. Indeed, the emergence of inhibition by noradrenaline after sleep deprivation is functionally equivalent to a decreased efficacy of the hcrt/orx system, a situation that occurs in the sleep disorder narcolepsy (Chemelli et al., 1999; Lin et al., 1999; Peyron et al., 2000; Thannickal et al., 2000; Mignot et al., 2002). This condition, which is accompanied by a decreased ability to maintain wakefulness, is thought to result from a decreased release of the hcrt/orx peptide on multiple targets in the brain (Peyron et al., 1998) that are involved in maintaining the waking state (Jones, 2003). Therefore, the striking modification of responsiveness of hcrt/orx neurons to noradrenaline observed in the present study might contribute to the increasing sleepiness that accompanies sleep deprivation.

\section{References}

Alfoldi P, Tobler I, Borbely AA (1990) Sleep regulation in rats during early development. Am J Physiol 258:R634-R644.

Bayer L, Eggermann E, Serafin M, Grivel J, Machard D, Muhlethaler M, Jones BE (2005) Opposite effects of noradrenaline and acetylcholine upon hypocretin/orexin versus melanin concentrating hormone neurons in rat hypothalamic slices. Neuroscience 130:807-811.

Beuckmann CT, Yanagisawa M (2002) Orexins: from neuropeptides to energy homeostasis and sleep/wake regulation. J Mol Med 80:329-342.

Borbely AA, Achermann P (2000) Homeostasis of human sleep and models of sleep regulation. In: Principles and practice of sleep medicine (Kryger MH, Roth T, Dement WC, eds), pp 377-390. Philadelphia: Saunders.

Chemelli RM, Willie JT, Sinton CM, Elmquist JK, Scammell T, Lee C, Richardson JA, Williams SC, Xiong Y, Kisanuki Y, Fitch TE, Nakazato M, Hammer RE, Saper CB, Yanagisawa M (1999) Narcolepsy in orexin knockout mice: molecular genetics of sleep regulation. Cell 98:437-451.

Cirelli C, Gutierrez CM, Tononi G (2004) Extensive and divergent effects of sleep and wakefulness on brain gene expression. Neuron 41:35-43.

de Lecea L, Kilduff TS, Peyron C, Gao X, Foye PE, Danielson PE, Fukuhara C, Battenberg EL, Gautvik VT, Bartlett FS, Frankel WN, van den Pol AN, Bloom FE, Gautvik KM, Sutcliffe JG (1998) The hypocretins: hypothalamus-specific peptides with neuroexcitatory activity. Proc Natl Acad Sci USA 95:322-327.

Eggermann E, Bayer L, Serafin M, Saint-Mleux B, Bernheim L, Machard D, Jones BE, Muhlethaler M (2003) The wake-promoting hypocretinorexin neurons are in an intrinsic state of membrane depolarization. J Neurosci 23:1557-1562.

Finelli LA, Baumann H, Borbely AA, Achermann P (2000) Dual electroencephalogram markers of human sleep homeostasis: correlation between theta activity in waking and slow-wave activity in sleep. Neuroscience 101:523-529.

Grivel J, Tobler I, Mühlethaler M, Serafin M (2004) Following sleep deprivation the excitation of rat hypocretin/orexin neurones by noradrenaline reverses to inhibition. Soc Neurosci Abstr 30:318.08.

Hara J, Beuckmann CT, Nambu T, Willie JT, Chemelli RM, Sinton CM, Sugiyama F, Yagami K, Goto K, Yanagisawa M, Sakurai T (2001) Genetic ablation of orexin neurons in mice results in narcolepsy, hypophagia, and obesity. Neuron 30:345-354.

Huber R, Deboer T, Tobler I (2000) Topography of EEG dynamics after sleep deprivation in mice. J Neurophysiol 84:1888-1893.
Huber R, Ghilardi MF, Massimini M, Tononi G (2004) Local sleep and learning. Nature 430:78-81.

Jones BE (2003) Arousal systems. Front Biosci 8:S438-S451.

Li Y, van den Pol AN (2005) Direct and indirect inhibition by catecholamines of hypocretin/orexin neurons. J Neurosci 25:173-183.

Li Y, Gao XB, Sakurai T, van den Pol AN (2002) Hypocretin/orexin excites hypocretin neurons via a local glutamate neuron-A potential mechanism for orchestrating the hypothalamic arousal system. Neuron 36:1169-1181.

Lin L, Faraco J, Li R, Kadotani H, Rogers W, Lin X, Qiu X, de Jong PJ, Nishino S, Mignot E (1999) The sleep disorder canine narcolepsy is caused by a mutation in the hypocretin (orexin) receptor 2 gene. Cell 98:365-376.

Mignot E, Taheri S, Nishino S (2002) Sleeping with the hypothalamus: emerging therapeutic targets for sleep disorders. Nat Neurosci 5 [Suppl 1]:1071-1075.

Nishino S, Ripley B, Overeem S, Lammers GJ, Mignot E (2000) Hypocretin (orexin) deficiency in human narcolepsy. Lancet 355:39-40.

Peyron C, Tighe DK, van den Pol AN, de Lecea L, Heller HC, Sutcliffe JG, Kilduff TS (1998) Neurons containing hypocretin (orexin) project to multiple neuronal systems. J Neurosci 18:9996-10015.

Peyron C, Faraco J, Rogers W, Ripley B, Overeem S, Charnay Y, Nevsimalova S, Aldrich M, Reynolds D, Albin R, Li R, Hungs M, Pedrazzoli M, Padigaru M, Kucherlapati M, Fan J, Maki R, Lammers GJ, Bouras C, Kucherlapati R, et al. (2000) A mutation in a case of early onset narcolepsy and a generalized absence of hypocretin peptides in human narcoleptic brains. Nat Med 6:991-997.

Sakurai T, Amemiya A, Ishii M, Matsuzaki I, Chemelli RM, Tanaka H, Williams SC, Richardson JA, Kozlowski GP, Wilson S, Arch JR, Buckingham RE, Haynes AC, Carr SA, Annan RS, McNulty DE, Liu WS, Terrett JA, Elshourbagy NA, Bergsma DJ, et al. (1998) Orexins and orexin receptors: a family of hypothalamic neuropeptides and $\mathrm{G}$ protein-coupled receptors that regulate feeding behavior. Cell 92:573-585.

Siegel JM, Moore R, Thannickal T, Nienhuis R (2001) A brief history of hypocretin/orexin and narcolepsy. Neuropsychopharmacology 25:S14-S20.

Sutcliffe JG, de Lecea L (2002) The hypocretins: setting the arousal threshold. Nat Rev Neurosci 3:339-349.

Taheri S, Zeitzer JM, Mignot E (2002) The role of hypocretins (orexins) in sleep regulation and narcolepsy. Annu Rev Neurosci 25:283-313.

Thannickal TC, Moore RY, Nienhuis R, Ramanathan L, Gulyani S, Aldrich M, Cornford M, Siegel JM (2000) Reduced number of hypocretin neurons in human narcolepsy. Neuron 27:469-474.

Tobler I (2000) Phylogeny of sleep regulation. In: Principles and practice of sleep medicine (Kryger MH, Roth T, Dement WC, eds), pp 72-81. Philadelphia: Saunders.

Tobler I, Borbely AA (1986) Sleep EEG in the rat as a function of prior waking. Electroencephalogr Clin Neurophysiol 64:74-76.

Tobler I, Gaus SE, Deboer T, Achermann P, Fischer M, Rulicke T, Moser M, Oesch B, McBride PA, Manson JC (1996) Altered circadian activity rhythms and sleep in mice devoid of prion protein. Nature 380:639-642.

Tononi G, Cirelli C (2003) Sleep and synaptic homeostasis: a hypothesis. Brain Res Bull 62:143-150.

Vyazovskiy V, Achermann P, Borbely AA, Tobler I (2004) Interhemispheric coherence of the sleep electroencephalogram in mice with congenital callosal dysgenesis. Neuroscience 124:481-488.

Vyazovskiy VV, Welker E, Fritschy JM, Tobler I (2004) Regional pattern of metabolic activation is reflected in the sleep EEG after sleep deprivation combined with unilateral whisker stimulation in mice. Eur J Neurosci 20:1363-1370.

Yamanaka A, Muraki Y, Tsujino N, Goto K, Sakurai T (2003) Regulation of orexin neurons by the monoaminergic and cholinergic systems. Biochem Biophys Res Commun 303:120-129. 